\title{
Laboreal
}

Volume $17 \mathrm{~N}^{\circ} 1$ | 2021

Trabalhar hoje: mudanças, permanências, estratégias, reinvenções

\section{Psicologia e história}

Psicología e historia

Psychologie et histoire

Psychology and history

\section{Lucien Febvre}

Tradutor. João Viana Jorge (joaojorg@gmail.com)

\section{(2) OpenEdition Journals}

\section{Edição electrónica}

URL: https://journals.openedition.org/laboreal/18010

DOI: $10.4000 /$ laboreal. 18010

ISSN: 1646-5237

\section{Editora}

Universidade do Porto

\section{Refêrencia eletrónica}

Lucien Febvre, «Psicologia e história», Laboreal [Online], Volume 17 NN$^{0} 1$ | 2021, posto online no dia 18 junho 2021, consultado o 20 junho 2021. URL: http://journals.openedition.org/laboreal/18010 ; DOl: https://doi.org/10.4000/laboreal.18010

Este documento foi criado de forma automática no dia 20 junho 2021.

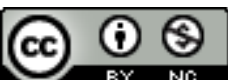

Laboreal está licenciado com uma Licença Creative Commons - Atribuição-NãoComercial 4.0 Internacional. 


\title{
Psicologia e história
}

\author{
Psicología e historia \\ Psychologie et histoire \\ Psychology and history
}

\section{Lucien Febvre}

Tradução : João Viana Jorge (joaojorg@gmail.com)

\section{REFERÊNCIA}

Texto original : Febvre, L. (1938). Psychologie et histoire. In H. Henri Wallon (Dir.), La vie mentale. L'Encyclopédie Française, Tome VIII (pp. 8'12-3 - 8'12-7). Paris : Larousse.

1 Aptidão para descobrir correlações : eis, em muitos casos, uma das definições mais satisfatórias do talento científico : pense-se no grande clínico que agrupando indícios e sintomas dispersos realmente "inventa" e "cria" uma doença nova. Aptidão para negociar acordos, intercâmbios entre disciplinas próximas : eis, para uma ciência em vias de expansão uma não menos acertada definição de progresso. Traduz-se por vezes de uma outra maneira esta verdade oriunda da experiência : "as grandes descobertas processam-se sempre nas próprias fronteiras das ciências".

2 Psicologia, história : uma aliança e suas finalidades - Desde logo a psicologia, conhecimento científico da função mental, tem necessariamente de estabelecer estreitas ligações com o conhecimento científico da função social, isto é, a sociologia em vias de elaboração; e que ela deva não menos necessariamente estabelecer relações persistentes com determinadas disciplinas que mantemos confundidas sob o nome tradicional de história - eis o que não necessita de longas explicações. Que aliás, no momento atual, estas relações não possam senão ser bastante dececionantes, é o que se poderá esperar. A psicologia acaba apenas de se desembaraçar das controvérsias filosóficas para se instalar no terreno sólido da pesquisa experimental. A sociologia só tem nome há apenas um século e contém substância ainda há menos tempo. Quanto às disciplinas que durante um século se separaram do magma confuso da história não têm 
sequer estado civil. Razão acrescida para que nesta Enciclopédia, que não pretende apenas limitar-se a estereotipar os resultados adquiridos, não se negligenciem os aspetos movediços da vida das ciências humanas.

3 Entre psicólogos, sociólogos e historiadores qual seria à primeira vista um desafio de um debate acerca das competências e atribuições? Evidentemente o conhecimento do indivíduo. "A psicologia, dizia Baldwin, trata do indivíduo, a sociologia do grupo". Quanto à história, imagino que Baldwin, se a tivesse definido, teria nela encerrado, o indivíduo e o grupo e afirmado que, armada com os resultados adquiridos pela psicologia e a sociologia, ela esforçar-se-ia por definir, no quadro do passado, as suas recíprocas relações. Excelentes noções para estudantes: claras, simples e fornecem chaves de uso fácil. o mal, é que quando utilizadas deixam sempre fechada a segunda porta. Em vez de dissertar no abstrato e de traçar no papel que suporta a escrita com limites bem desenhados, coloquemo-nos frente às realidades e apliquemos o método correto : complicar o que parece demasiado simples.

\section{Do ponto de vista da história}

4 Qual é o objeto de estudo do historiador ? A opinião comum responde : por um lado, os movimentos confusos de massas de homens anónimos, indistintas, indiscerníveis, dedicadas de alguma maneira às ocupações menos consideradas e valorizadas da história ; por outro lado, emergindo deste cinzentismo, e destacando-se com claridade da penumbra, a ação dirigente de um certo número de indivíduos qualificados como "personagens históricas".

5 As massas são pouco conhecidas. Há poucos meios para as conhecer. Épocas inteiras não nos deixaram sobre elas qualquer testemunho direto e detalhado. Aristocrática nas suas origens, a história não teve olhos durante séculos e muito frequentemente não os tem ainda senão para reis e príncipes, os condutores de povos e de exércitos; os homens "que fazem história", Menschen die Geschischte machen - é o título de uma volumosa recolha de biografias históricas editada recentemente na Alemanha. Assim sendo, as relações entre a psicologia e a história estabelecem-se, de acordo com a opinião vulgar, muito simplesmente. As massas anónimas? Serão justificação de uma psicologia coletiva fundada no estudo das massas atualmente acessíveis que estenderia sem esforço (supostamente pelo menos) as suas conclusões às massas de outrora, às massas históricas. Quanto aos indivíduos diferenciados, às personagens históricas (essas) pertencem naturalmente à psicologia individual. Os documentos que lhes dizem respeito, dos quais muitos comportam uma interpretação psicológica da sua atividade e do seu carácter serão de fácil apreensão pelos psicólogos. Engrossarão o tesouro das suas observações. Inversamente, as conclusões que estes podem tirar do estado dos casos humanos que têm sob os seus olhos permitirão aos observadores interpretar e compreender melhor a conduta e a ação dos dirigentes das sociedades de outrora, autênticos artesãos da história humana.

E, portanto, eis-nos novamente e sempre frente ao binómio indivíduo - sociedade. Mas continuemos a afunilar o problema mais de perto.

7 O que é, na história, o indivíduo - O que são esses indivíduos prestigiados, essas personalidades emergentes, essas personagens históricas? Respondemos há pouco tempo, aquando da terceira Semana internacional de síntese onde se discutiu a individualidade : são os autores responsáveis por uma grande obra histórica. Mas o que 
é uma grande obra histórica? Um conjunto de factos recolhidos, agrupados, organizados pelos historiadores de tal modo que constituem um dos anéis de uma dessas grandes cadeias de factos homogéneos e distintos, factos políticos, económicos, religiosos, etc., com os quais, nós historiadores construímos a rede mais ou menos apertada do passado histórico da humanidade. Essas cadeias é a história que as forja e as reforja sem cessar na sua necessidade de organizar o passado, de introduzir clareza e ordem no conjunto em movimento perpétuo, no borboletear e cintilar dos factos que sem lei aparente se chocam, se misturam e reciprocamente se comandam à volta de cada homem, em cada momento da sua vida - e, portanto, da vida das sociedades em que participa.

8 O que é a obra histórica - Grandes encadeamentos, grandes desenvolvimentos: porquê grandes? Porque é preciso distinguir por entre as obras humanas as que não interessam senão a um pequeno e determinado grupo de homens e as outras que, por cima das fronteiras desses pequenos grupos, tendem a uni-los ou pelo menos a orientálos numa mesma direção. Tais como as religiões, na medida em que não sejam religiões fechadas em grupos, interditas a todos os não participantes desses grupos. Tais como os grandes sistemas de ideias e de doutrinas que se expandem para fora das fronteiras e interligam os homens de todos os grupos. Tais como igualmente as obras políticas: organizações e revoluções, conquistas e expansões com todo o cortejo de adesões de um lado e de resistências do outro lado. Obras históricas ? Sim, na medida em que elas não são unicamente o fruto da violência, mas beneficiam da colaboração do tempo e da adesão dos homens a quem tendo sido inicialmente impostas acabam por as aceitar, adotando-as mesmo e em seguida difundindo-as. Sim, na medida em que não são realizadas por alguns homens unicamente para uso e proveito de alguns grupos - mas podem exprimir um esforço conjunto para organizar a vida das massas humanas. Sim, na medida em que o que foi inicialmente obra de particularismos e se se quiser de egoísmos, se transforma em obra civilizacional. Ora, a civilização não será, com efeito, como mostrou Marcel Mauss, um conjunto de factos que não se limitam a uma dada sociedade, mas que se mostram suscetíveis de migrações e de implantação em domínios por vezes bem distanciados e muito diferentes do seu domínio original? Feitos viajantes, transportáveis, que saindo de um grupo se fazem tomar de empréstimo, adotar, utilizar por outros grupos?

9 Como o indivíduo colabora com o grupo - Assim, obra histórica é : a que para além do local e do nacional visa a humanidade. A que se afirma suscetível de irradiação humana e de expansão pacífica. E então a personagem histórica? Responde a uma exigência elementar da crença comum. Qualquer relógio pressupõe um relojoeiro. Toda a obra histórica postula um autor. É necessário que entre em jogo a categoria fundamental da criação : pai-filho.

O pai da obra histórica é a personagem histórica. Se se preferir, invertendo os termos, a personagem histórica é o homem a quem a crença comum atribui a paternidade duma obra histórica; simplificação necessária e mnemotécnica cómoda. Mas se o que acabamos de dizer é verdade? Se o autor, e não o "pretenso" autor duma obra de organização coletiva de repercussão duradoura, isto é, o autor "garantido" de uma grande obra científica, literária, filosófica ou religiosa que parece sair verdadeiramente do seu cérebro (Darwin, Shakespeare, Marx, Calvin), não souber conferir eficácia a essa obra sem a colaboração, sem a participação ativa do grupo que a adotou ? Se é normal o drama do homem que lança uma ideia e que a ele retorna totalmente deformada, 
transformada e desnaturada pelo meio ? Se é típica a aventura de Martin Luther, pai autêntico do luteranismo, mas confessando cem vezes a sua perturbação, o seu desalento quando teve de constatar o quanto as massas, desde o início, deformaram as suas ideias, apropriando-se delas e fazendo-lhes sofrer a sorte que conhecem todos os grandes criadores de ideias ou de sentimentos : essa deformação, essa transformação, por vezes inversão total das suas ideias mas de que têm de suportar apesar de tudo perante a história uma paternidade que não é mais que ilusória e que frequentemente lhes pesa, que quereriam repudiar, que têm que aceitar?

o grupo no indivíduo : linguagem e técnica - Além de personagem histórica, onde está o ser humano que pode ser considerado uma potência autónoma, independente e isolada, uma espécie de criação original e espontânea, enquanto toda a pessoa humana sofre tão fortemente influências, umas vindas do fundo dos tempos, outras exercidas do modo mais imediato pelo meio atual e desde logo veiculadas por esses dois agentes, por excelência, de penetração da sociedade no indivíduo : a linguagem e a técnica ?

Linguagem : o mais potente de todos os meios de ação do grupo sobre o indivíduo. Linguagem, técnica lentamente elaborada pela humanidade e chegada ao seu estado atual, ao seu estado perpetuamente variável e movediço depois de, não digo séculos, mas, milénios de trabalho. Linguagem carregada, ao fim desse tempo, de toda a série de diferenciações, de dissociações, de categorias que a humanidade conseguiu criar pouco a pouco. Linguagem cuja ação se junta, por um lado, à dos mitos que desempenharam papel de técnicas para a humanidade quando ainda lhe fazia falta a aparelhagem capaz de lhe fornecer o domínio das coisas e, por outro lado, à ação das próprias técnicas tão fortemente aparentadas entre elas numa mesma época, tão fortemente participantes de um mesmo estilo suscetível de ser datado sem erro. Tudo isso, numa palavra, permite dizer que o indivíduo não é senão o que a sua época e o seu meio social permitem que ele seja.

13 Mas então a alternativa : indivíduos ou massas? Se se preferir, outro enunciado do mesmo problema : indivíduos ou sociedades ? O meio social penetra desde logo o autor da obra histórica, enquadra-o e em larga medida determina-o na sua criação. E quando esta está concluída ou morre, ou então para viver é necessário que ela receba a colaboração ativa, a temível colaboração das massas, o peso do meio, irresistível e constrangedor. Noutros termos, a sociedade é para o homem uma necessidade, uma realidade orgânica. Por si só, para retomar uma expressão de H. Wallon, "a linguagem implica a sociedade como os pulmões (d'une espèce aérienne) implicam a existência da atmosfera". E, desta sociedade, recebe o indivíduo as suas determinações ; são para ele um complemento necessário ; "ele tende para a vida social, como para o seu estado de equilíbrio".

\section{Do ponto de vista da psicologia}

14 Agora tudo nos parece menos simples que à partida. Se, em qualquer indivíduo há lugar a distinguir primeiro uma dada pessoa, caracterizada mais ou menos claramente, depois um conjunto de traços a si próprio pertencentes e cuja conjunção se faz segundo uma fórmula e com um doseamento muito particular; se se devem recolher a seguir nesse mesmo indivíduo, quer um representante da espécie humana portador das mesmas características distintivas dos membros de um determinado grupo dessa espécie, quer sobretudo um participante duma sociedade bem determinada e datada: 
por um lado o contraste atenua-se tão singularmente entre o indivíduo e a sociedade que deixa de haver lugar a opor esquematicamente um ao outro; por outro lado, o método de investigação começa a definir-se com clareza.

Os três deveres do psicólogo - Três séries de questionamentos, cada um por sua vez, o ocuparão. Deverá começar por se entregar à pesquisa do que o homem deve ao seu meio social : psicologia coletiva. Poderá, deverá mesmo perguntar-se em seguida o que o homem deve ao seu organismo específico : psicologia específica ou psicofisiologia. Poderá estudar por fim o que um tal ser humano deve às particularidades individuais da sua fisiologia, aos acasos da sua estrutura, aos acidentes sobretudo da sua vida social : psicologia diferencial. Em boa lógica, aliás, esta última não deverá intervir senão depois do aprofundamento dos duas precedentes. E enquanto estas não tiverem feito progressos decisivos, enquanto no caos dos casos individuais os psicólogos não tenham conseguido substituir as espécies psicológicas bem caracterizadas, como no caos dos sintomas os médicos substituem as espécies mórbidas amplamente concebidas; enquanto não tiver havido criação de "tipos" permitindo, face ao indivíduo, a operação sempre delicada do diagnóstico que consiste em integrar o caso individual em qualquer uma das espécies previamente criadas - a psicologia diferencial deverá resignar-se a conservar qualquer coisa de empírico. E isto, sendo verdadeiro na psicologia atual é-o ainda mais na psicologia retrospetiva. Se se quiser, na psicologia histórica.

\subsection{O problema da psicologia histórica}

16 Porque há de facto um problema especial na psicologia histórica. Quando, nas suas dissertações, nos seus tratados, os psicólogos nos falam das emoções, das decisões, dos raciocínios do homem, na realidade é das nossas emoções, das nossas decisões, dos nossos raciocínios que estão a tratar. Do nosso lote, nosso dos homens brancos da Europa ocidental, integrados, neste século XX, em grupos de muito velha cultura. Ora como poderíamos nós historiadores ajudarmo-nos a interpretar as démarches de homens de outrora, graças a uma psicologia resultante da observação de homens do século XX ? E como é que eles, psicólogos, poderiam encontrar, nos dados que a história lhes fornece (ou deveria fornecer) sobre a mentalidade dos homens de outrora, material com que pura e simplesmente enriqueceriam uma experiência adquirida no contacto com os seus contemporâneos? No máximo esta experiência poderá muni-los de tipos de comparações que lhes permitam melhor apreender as diferenças que os nossos ancestrais, diretos ou não, longínquos ou próximos, apresentam em relação a nós.

Na realidade, nem a psicologia dos nossos psicólogos contemporâneos se aplica ao passado, nem a psicologia dos nossos ancestrais encontra aplicação possível aos homens de hoje. Quer se trate, tanto dos heróis da história, das personagens históricas nossas conhecidas através de um maior ou menor número de documentos biográficos $\mathrm{e}$ de retratos físicos e mentais - como das massas anónimas nas quais não nos preocupamos a analisar psicologicamente os elementos, nem a caracterizar globalmente as reações : num como no outro caso "não se trataria, para usar os termos de Ch. Blondel (Introduction à la psychologie collective, p. 197), de obstinar-se em determinar de plano maneiras universais de sentir, de pensar e de agir, talvez inexistentes e em qualquer caso atualmente inacessíveis. Considerando isoladamente os grupos humanos espalhados no espaço e no tempo, o seu papel é, ao contrário, de 
descrever os sistemas mentais próprios de cada um e de os analisar tanto quanto possível, procurando perceber o mecanismo da sua elaboração, o jogo do seu desenvolvimento e a natureza das relações que ligam entre eles os seus elementos". Não poderia dizer-se melhor nem mais claramente denunciar o perigo: o de querer passar diretamente, e sem mesmo suspeitar a dificuldade, dos sentimentos e das ideias que são nossas aos sentimentos e às ideias que palavras parecidas, que as mesmas palavras geradoras das mais graves confusões, pela sua hipotética e falaciosa identidade, servem sempre para identificar, por vezes a alguns séculos de distância. Serão necessários dois ou três exemplos?

Alguns anacronismos psicológicos - Não vamos procurá-los muito longe. Lembremonos que, como refere Charles Blondel (obra citada, p. 202), "se tomarmos duas coletividades suficientemente afastadas uma da outra no tempo ou no espaço, a diferença de mentalidades correspondentes saltar-nos-á aos olhos"; enquanto que se forem mais próximas uma da outra se necessitará de esforços e de pesquisas por vezes longos e delicados para discernir as divergências, aliás frequentemente consideráveis. Não nos dirijamos, pois, nem aos primitivos, dos quais os notáveis estudos de Lucien Lévy-Bruhl se esforçam por analisar as maneiras de sentir, de pensar e de agir (as suas observações convêm essencialmente à função não de uma história, mas de uma préhistória, ou se se preferir de uma paleontologia psicológica), nem a esses chineses cujos livros, tão ricos, de Granet nos permitem comparar às nossas, as démarches intelectuais.

o apego à vida - Coloquemos simplesmente uma questão: a que liga mais, ou se se quiser, a que renuncia mais dificilmente o homem de hoje? Questão que já coloca reservas, porque : homem, qual homem ? - Mas concordaremos em responder sem mais reflexão : é à sua vida. À sua própria vida. Sobre isso, abramos qualquer das obras de Frazer. E nesses livros clássicos recolheremos mãos cheias de factos surpreendentes (pelo menos para nós) que nos mostrarão entre sociedades relativamente próximas e as nossas sociedades, diferenças, contrastes verdadeiramente enormes na apreciação desse valor que a própria "natureza" pareceria promover para a primeira de todas as posições. Aí aprenderíamos do mesmo modo que povos inteiros, durante séculos e séculos não protegeram, mas destruíram os seus próprios filhos oferecendo-os espontaneamente ao sacrifício. Aí aprenderíamos que essa união, para nós indissolúvel, entre a divindade e a imortalidade, se não a eternidade, milhões e milhões de seres humanos ignoraram-na e ignoram-na ainda, acreditaram, acreditam na morte dos deuses, criaram os seus deuses mortais à sua imagem. Histórias antigas? Sem dúvida. Mas abramos o tomo IX de Histoire littéraire du sentiment religieux en France, do abade Henri Brémond. Intitula-se : La vie chrétienne sous l'ancien regime e contém sobre a arte de morrer um capítulo surpreendente. Aí se verá com toda o à-vontade como há menos de três séculos se tratavam os moribundos com uma espécie de crueldade (pelo menos a nosso ver) que nos transporta duma penada, particularmente longe de nós próprios e da nossa mentalidade.

A mobilidade do humor na idade média - Outros exemplos. Nas vidas romanceadas que nos últimos anos vimos multiplicarem-se a seu bel-prazer - um prazer talvez para os editores que não para o leitor culto - o que é que choca o historiador e como se explica o seu mau humor perante esse excesso biográfico ? Serão os erros factuais, a bem dizer inevitáveis, os descuidos, confusões, inépcia repetida de autores sem competência nem preparação ? Seriam os embirrentos hábitos de pilhagem, o roubo violento organizado 
ou a cínica ocultação do autor em obras de verdadeiros historiadores pelos folhetinistas apressados da historiografia? E não! É algo de bem mais grave : o anacronismo, o perpétuo e irritante anacronismo de homens que se projetam, tal qual são, no passado, com os seus sentimentos, as suas ideias, os seus preconceitos morais e intelectuais e que, tendo travestido Ramsès II, Sesóstris, Júlio César, Carlos Magno ou Filipe II ou mesmo Luís XIV em Dupont ou Durand 1938 encontram nos seus heróis o que acabam de lhes atribuir admirando-se amavelmente e concluindo a sua "análise" por este nil novi desconcertante : "Assim é o homem, sempre igual a si próprio".

Ora, sem ir mais longe, façamos apelo á nossa experiência de historiador. É impossível estudar a vida, os hábitos, as maneiras de ser e de agir dos homens da idade média (uma idade média que se prolonga até ao século XVI e mesmo mais para diante), é impossível ler nos textos autênticos, relatos sobre príncipes, festas, procissões, execuções judiciais, sermões populares, etc. sem chocar com a espantosa mobilidade do humor, com a permeabilidade excessiva às impressões do exterior que manifestam os homens desse tempo. Prestes a irritarem-se, prestes a entusiasmarem-se, sempre prestes a desembainhar a espada, mas não menos a se abraçarem. Dança-se e chora-se. Cheira-se o sangue e depois as rosas. É preciso lembrar, escreve num livro muito sugestivo o escritor holandês Huizinga (Le déclin du moyen-âge, 1932, p. 16), é preciso lembrar essa recetividade, essa facilidade das emoções, essa propensão para as lágrimas, esses volteios espirituais, se se pretende conceber a aspereza do gosto, a violência da cor que tinha a vida nesses tempos". Sem dúvida: mas é preciso sobretudo explicar. E a explicação não é simples. Põe em jogo uma multitude de dados que os historiadores até agora não se preocuparam em reunir, agrupar num corpo. Ao que não pensaram dar o verdadeiro valor.

Condições de vida e mentalidade - Homens em grandes contrastes? Mas a sua vida material - já o assinalávamos há quinze anos numa série de artigos da Revue des cours et conférences (1925) - não era ela própria toda feita de contrastes? Pensemos em coisas muito simples, muito pesadas, das quais nunca medimos esse peso.

Dia-noite - O que é para nós, homens do século XX, o contraste entre o dia e a noite ? Geralmente já nada. Um botão, um gesto e a luz elétrica substitui a luz solar. Mestres do dia e da noite é com virtuosismo que o fazemos. E os homens da idade média ? E os do século XVI? Não dominavam isso, as pobres gentes, eles que nem mesmo tinham lamparinas de azeite quando a noite caía nem mesmo velas. Uma vida contada, ritmada a cada dia pela sucessão das trevas e da luz; uma vida truncada em duas partes, a noite e o dia ; o branco e o negro ; o silêncio absoluto e o ruído do trabalho - pode acreditarse que tenha podido engendrar nos homens os mesmos hábitos mentais, as mesmas maneiras de pensar, de sentir, de querer, de agir e de reagir que a nossa vida estabilizada, regularizada, despojada de choques, de contrastes e de confrontações brutais?

Inverno-verão - Dia e noite - mas inverno e verão ? Quer dizer frio e quente ? Existe ainda inverno para nós? Quando queremos : mas ainda assim é sempre acompanhado por um estio que não depende senão de nós. Todo o dia a esquiar na neve. Mas à noite, no hotel aquecido a $20^{\circ}$. Aquecido em toda a parte. Quando se entra numa casa, hoje, no pino do inverno, não se sente na cara o hálito quente dos radiadores? Despimo-nos. Mas quando se entrava em casa no século XVI, em janeiro, sentia-se o frio cair-nos nos ombros : o frio imóvel, silencioso e negro dos alojamentos sem aquecimento. Já se tiritava antecipadamente. Tal como se tiritava na igreja. Como se tiritava no palácio do 
rei a despeito das grandes lareiras que consumiam árvores inteiras. $\mathrm{E}$ o primeiro gesto do homem que regressava (a casa) não era o de tirar o sobretudo era o de vestir um casacão mais quente do que aquele com que tinha saído. E o de enfiar na cabeça um gorro de forro mais espesso do que o da rua. Inverno - verão : contrastes adoçados para os mais humildes dos homens do nosso tempo. Contrastes de uma violência selvagem para os mais faustosos, os mais ricos dos homens de outrora. E sem dúvida - mas cabe aos psicólogos no-lo dizer : igualização das condições de vida material, igualização dos homens: as duas coisas não se sucedem, não é lógico que se arrastem, não se condicionam de todo?

Fortúnio - infortúnio - E as condições de segurança ? Segurança nas casualidades : um incêndio na atualidade, um acidente, uma morte prematura ? O seguro atua. Outrora? Reparemos que não se trata de casos individuais. Quando o fogo se ateava numa das extremidades de um bairro de uma cidade com casas cobertas com placas de madeira empurrado por um vento violento, consumia totalmente esse bairro arrasando totalmente em alguns minutos todo um aldeamento, surpreendidos durante a noite, sem meios de defesa, incapazes de salvar mesmo os seus animais - eram dez, vinte, cem famílias que bruscamente viam as suas ligações deslaçar-se: as crianças partiam ao abandono pelas estradas, perdendo-se de vista, não mais sabendo onde encontrar os seus irmãos e as suas irmãs. Segurança de vida, nada menos : não desenvolvamos.

o capítulo da alimentação - E o imenso capítulo da alimentação, das suas condições e das suas influências? A psicologia das populações sobre nutridas, em períodos de prosperidade e dispondo de alimentos ricos e variados em abundância, é a de, pode ser a de populações perpetuamente subalimentadas construindo um regime de vida precário nas margens da inanição e perecendo em massa como esses esquimós de quem fala num outro volume da Encyclopédie, Lucie Randouin - desde quando, por filantropia dos europeus compassivos, introduzem na sua dieta alimentos mais ricos que rompem com o equilíbrio precário da sua ração a que os pioneiros da nova ciência da alimentação atribuem tanta importância?

o testemunho de John Bull - Será necessário lembrar que a idade média foi uma época de permanente subalimentação, de penúria e de fome suspensas em determinados dias por comezainas anormais? E esse regime precisaria de admitir que engendrava, que conservava homens da mesma contextura física e mental que os nossos próprios regimes - os nossos regimes de gordos sedentários, fazendo suceder ao martírio do famélico o martírio do obeso? Pensemos simplesmente na sucessão brutal dessas imagens de povos, registadas na retina dos seus próprios vizinhos; pensemos na população de rãs macilentas, brancas e esfaimadas, que os ingleses do século XVIII imaginavam, e dúvida não era sem razão que imaginavam, vivendo nas margens do Sena enquanto eles próprios se reconheciam no John Bull, o apoplético - copiosamente alimentado a carnes vermelhas e sangrentas regadas com o álcool das cervejas : tantas sugestões e solicitações de estudos que não são feitos e que seria necessário fazer.

\section{Conclusão : colaboração necessária}

Não continuemos. Dissemos o suficiente para mostrar que se nos impedirmos de projetar o presente, o nosso presente, no passado, o que é a lei fundamental da história, se nos recusarmos o anacronismo psicológico, o pior de todos, o mais insidioso e o mais grave, se pretendermos esclarecer todas as démarches da sociedade e em primeiro 
lugar as mentais pelo exame das suas condições gerais de existência, é evidente que não poderemos tomar como válidas, no passado que tentaremos assim inventariar, as descrições e as constatações dos nossos psicólogos, operando com os dados que a nossa época lhes fornece. E é não menos evidente que uma verdadeira psicologia histórica não será possível senão através do entendimento, negociado com clareza, entre o psicólogo e o historiador. Este orientado por aquele. Mas aquele, estreitamente tributário do segundo e obrigado a tomar para si o cuidado de lhe criar as condições de trabalho. Trabalho em colaboração. Trabalho de equipa para ser mais claro.

29 A próxima tarefa - E, com efeito, inventariar, primeiro em detalhe, e depois reconstruir, para a época estudada, o material mental de que dispunham os homens dessa época; por um possante esforço de erudição, mas também de imaginação, reconstituir o universo, todo o universo físico, intelectual, moral no meio do qual cada uma das gerações que a precederam se movimentaram; adquirir um pensamento límpido e seguro de que, por um lado a insuficiência das noções de facto sobre este ou aquele assunto, por outro, a natureza do material técnico em uso pela sociedade naquela época que se trata de estudar, engendraria necessariamente lacunas e deformações nas representações que essa coletividade histórica interiorizou do mundo, da vida, da religião, da política; dar-se conta enfim, para usar (emprestada) a frase de Wallon, "de que o universo onde só a força muscular do homem está disponível para os seres concretos que se erguem perante ele", não é nem pode ser o mesmo universo em que o homem subjugou a eletricidade às suas necessidades e pode produzir essa eletricidade, subjugando as próprias forças da natureza ; compreender, numa palavra, que o universo não é mais um absoluto do que o "espírito" ou do que o "indivíduo", mas que vai incessantemente transformando-se com as invenções, com as civilizações que engendram as sociedades humanas, eis o próximo ideal, a finalidade que constitui o fim último do historiador; mas essa finalidade não será alcançada por historiadores isolados. Mesmo que tenham a preocupação de se ligarem aos psicólogos.

30 A sua enormidade e as suas condições - A tarefa é tão enorme que requer que se forneçam aos psicólogos os materiais de que têm necessidade para elaborar uma psicologia histórica válida. Tão enorme que não ultrapassa somente as forças e os meios de um só homem: ultrapassa o domínio de uma só ciência ou mesmo de duas. Pressupõe, para ser bem levada a cabo, a negociação de toda uma rede de alianças. Trata-se das técnicas? É preciso, tratando-se das sociedades civilizadas de outrora o socorro eficaz de uma arqueologia lançando a sua presa sobre tempos muito mais próximos de nós do que os tempos antigos propriamente ditos. É preciso, tratando-se de sociedades do presente, o socorro não menos eficaz duma etnologia não limitando de todo aos primitivos os seus esforços inventariais e tratando como os Lacandons de Soustelle ou os Tupi-Guarani de Métreaux populações muito mais próximas de nós e muito mais ricas em recursos de civilização. Identicamente, se se trata de linguagem, esta outra via cardinal de acesso ao social no indivíduo : é necessária a colaboração de filólogos erigindo esses inventários de línguas que não são feitos para os historiadores mas dos quais eles podem tirar tão grande partido : não os inventários globais dessas grandes línguas civilizacionais que fundem as contribuições de tantos grupos locais ou sociais diferentes e no-los entregam em bruto, mas esses inventários de patoá que interpretados pelo historiador de sociedades rurais fornecem tantos preciosos ensinamentos que só elas podem fornecer. Mas não é menos necessária a colaboração dos semantistas que, ao nos restituírem a história de palavras particularmente pesadas 
de sentido escrevem com precisão, da mesma penada, capítulos da história das ideias. É necessária a colaboração desses historiadores das línguas, como Meillet escrevendo a história da língua grega ou como Ferdinand Brunot seguindo passo a passo os destinos da língua francesa que referem o aparecimento, em determinada datas, de todo um contingente de palavras novas ou de novos sentidos dados a velhas palavras. É necessário, para passar de um jogo de signos a um outro, a colaboração dessas exegetas da iconografia que, com monumentos datados restituem a história das bem complexas sentimentalidades religiosas. É necessário... não prossigamos com a enumeração porque também tudo se resume numa palavra: são necessários espíritos alerta, inventivos, engenhosos que buscam colaborações e, perante qualquer trabalho intelectual, colocam a si próprios a questão do investigador : o que pode isso servir para mim ? E como utilizar o que não é feito para mim?

31 E, portanto, ao trabalho. O problema não é o da teoria. Não é o de saber se qualquer história (política, social, económica, intelectual) de grupos humanos deve ordenar-se em função de um "psicológico em primeiro lugar" desregrado, em torno de uma história do pensamento, do sentimento e da vontade recolhidos nas transformações cronológicas. Era a ideia ainda recente de Karl Lamprecht. Discutiremos noutro lado essas grandes teses doutrinais ; não estarão aqui em causa. Aqui trata-se simplesmente de apelar com os nossos votos à procura de um trabalho positivo urgente de que acabamos de registar as condições imediatas. Aqui trata-se de integrar uma psicologia histórica totalmente nova, a criar, na possante corrente de uma história que a encaminha como todas as coisas para o destino da humanidade - de uma humanidade que marcha sem saber para o que tende. 